\title{
Pharmacokinetics of micafungin in subjects with severe hepatic dysfunction
}

\author{
Nasrullah Undre • Benjamin Pretorius • \\ Paul Stevenson
}

Received: 8 October 2013/ Accepted: 20 May 2014/Published online: 3 June 2014

(C) The Author(s) 2014. This article is published with open access at Springerlink.com

\begin{abstract}
Micafungin is an echinocandin with potent activity against a broad range of fungal species, including Candida species. The pharmacokinetic and safety profiles of micafungin have been evaluated in individuals with mild-to-moderate hepatic dysfunction, but not in individuals with severe hepatic dysfunction. Therefore, the present study assessed the pharmacokinetics and safety of a single $100 \mathrm{mg}$ dose of micafungin in healthy subjects $(n=8)$ and subjects with severe hepatic dysfunction $(n=8)$. Mean maximum plasma concentration of micafungin and mean area under the plasma micafungin concentration-time curve extrapolated to infinity were lower in subjects with severe hepatic dysfunction $(7.3 \pm 2.4 \mu \mathrm{g} / \mathrm{mL}$ and $100.1 \pm 34.5 \mathrm{~h} \cdot \mu \mathrm{g} / \mathrm{mL}$, respectively) than in subjects with normal hepatic function $(10.3 \pm 2.5 \mu \mathrm{g} / \mathrm{mL}$ and $142.4 \pm 28.9 \mathrm{~h} \cdot \mu \mathrm{g} / \mathrm{mL}$, respectively). Mean clearance was higher in subjects with severe hepatic dysfunction $(1,098 \pm 347 \mathrm{~mL} / \mathrm{h})$ than in subjects with normal hepatic function $(728 \pm 149 \mathrm{~mL} / \mathrm{h})$. Concentrations of albumin in subjects with severe hepatic dysfunction were lower. Assessments of micafungin plasma protein binding suggested that the higher clearance in subjects with severe hepatic dysfunction may be due to higher unbound concentrations. However, the magnitude of the differences was not considered clinically meaningful and is comparable
\end{abstract}

\section{N. Undre $(\square)$}

Astellas Pharma Europe Ltd, 2000 Hillswood Drive,

Chertsey KT16 0RS, UK

e-mail: nas.undre@astellas.com

\section{B. Pretorius}

Parexel International, Bloemfontein, South Africa

P. Stevenson

Astellas Pharma GmbH Munich, Munich, Germany with exposures reported elsewhere for a 100-mg dose in patients treated for invasive candidiasis. Thus, dose adjustment in subjects with severe hepatic dysfunction is not warranted. Micafungin was well tolerated in all subjects throughout the study.

Keywords Hepatic - Liver - Micafungin · Pharmacokinetics $\cdot$ Safety

\section{Introduction}

Candidaemia and invasive candidiasis are the most common invasive fungal infections, and the incidence of these serious diseases is rising (Pfaller and Diekema 2007). In Europe, Candida albicans is responsible for $>50 \%$ of cases of invasive candidaemia; however, non-albicansrelated Candida infections are also increasing (Lass-Flörl 2009).

Micafungin is an injectable echinocandin antifungal agent that displays potent activity against a broad range of Candida species (Jarvis et al. 2004; Messer et al. 2006). It has demonstrated efficacy similar to that of liposomal amphotericin B and caspofungin for the treatment of invasive candidiasis and candidaemia (Kuse et al. 2007; Pappas et al. 2007) and to that of fluconazole for the treatment of oesophageal candidiasis (de Wet et al. 2005). Moreover, it exhibits superior efficacy and comparable safety to fluconazole for the prophylaxis of invasive fungal infections in patients undergoing haematopoietic stem cell transplantation (van Burik et al. 2004).

Micafungin is metabolised in the liver and is mainly excreted in bile (Fromtling 2002); it undergoes metabolism to three metabolites: M-1, formed by metabolism of the parent drug; M-2, formed by degradation of M-1; and M-5, 
formed by hydroxylation of the side chain of micafungin by CYP450 enzymes. However, metabolism by the CYP450 system plays only a minor role in the degradation of micafungin (Wiederhold and Lewis 2007).

Previous pharmacokinetic (PK) studies of micafungin have been conducted in healthy adults (Hebert et al. 2005a, b, c; Keirns et al. 2007), HIV-positive adults with confirmed oesophageal candidiasis (Undre et al. 2012a), adults and children with invasive candidiasis and candidaemia (Undre et al. 2012b, c), neonates with suspected candidaemia or invasive candidiasis (Benjamin et al. 2010) and subjects with mild-to-moderate hepatic dysfunction (Hebert et al. 2005b). The recommended daily dose for the treatment of adults with invasive candidiasis and candidaemia is $100 \mathrm{mg}$. This results in the following mean steadystate PK parameters: area under the plasma concentrationtime curve over dosage time interval 0-24 h ( $\left.\mathrm{AUC}_{0-24}\right)$, $97 \mathrm{~h} \cdot \mu \mathrm{g} / \mathrm{mL}$; maximum plasma concentration $\left(C_{\max }\right)$, $10.5 \mu \mathrm{g} / \mathrm{mL}$; clearance (CL), $1,168 \mathrm{~mL} / \mathrm{h}$ and half-life $\left(t_{1 / 2}\right)$, 14-15 h (Undre et al. 2012b).

In a study in subjects with moderate hepatic dysfunction (Child-Pugh score 7-9), AUC extrapolated to infinity $\left(\mathrm{AUC}_{\infty}\right.$ ) and $C_{\max }$ of micafungin were lower, and $\mathrm{CL}$ higher, compared with healthy subjects, but the differences were not considered to be clinically relevant (Hebert et al. 2005b). Exposure was comparable with that observed for a 100-mg dose in patients treated for invasive candidiasis (Undre et al. 2012b). Thus, dose adjustment was not considered necessary in subjects with mild-to-moderate hepatic dysfunction. However, there are no data on the PK and safety of micafungin in individuals with severe hepatic dysfunction. Therefore, this study was designed to characterise the PK and safety profiles of micafungin following administration of a single dose of $100 \mathrm{mg}$ to individuals with severe hepatic dysfunction.

\section{Methods}

\subsection{Subjects and study design}

This was a single-dose, open-label study in which subjects with severe hepatic dysfunction (Child-Pugh score 10-12) and healthy, control subjects were enrolled and matched 1:1 for age (within 10 years), weight (within $20 \%$ ), sex and race. All subjects were aged between 18 and 75 years and within $35 \%$ of their ideal body weight. Subjects were excluded from the study if they had received any prescribed systemic or topical medication within 14 days of receiving study drug, non-prescribed systemic or topical medication within 7 days (except vitamin or mineral supplements or paracetamol or contraceptives in healthy females) or any medications known to chronically alter drug absorption or elimination within 30 days. Subjects were also excluded if they had participated in a clinical study of a drug within the previous month, had a known history of lactose or gluten intolerance, clinically significant allergic disease, other significant illness within 3 months of the start of the study, multiple drug allergies or allergy to the micafungin drug class, supine blood pressure and supine pulse rate at screening higher than $150 / 100 \mathrm{mmHg}$ and 100 beats per min, respectively, or lower than $100 / 50 \mathrm{mmHg}$ and 40 beats per min, respectively, positive drug screen, pregnancy test or test for HIV antibodies or clinically relevant coagulation abnormalities. In addition, any subjects with medical history or clinical or laboratory findings indicative of acute or chronic disease that, in the opinion of the investigator, might influence study outcome, a history of any clinically significant neurological, gastrointestinal, renal, hepatic, cardiovascular, psychiatric, respiratory, metabolic, endocrine, haematological or other major disorder (normal hepatic function), or an invasive infection that required treatment (severe hepatic dysfunction) were also excluded from the study.

Eligibility was assessed by physical examination, vital signs, 12-lead electrocardiogram, drug and alcohol screen, clinical laboratory parameters and medical history conducted $\leq 15$ days before administration of study drug (Day 1) with confirmation of eligibility criteria on Day 1 . On Day-1, all subjects received a single dose of micafungin $100 \mathrm{mg}$. All eligible subjects were hospitalised for the study period (Day-1 to Day 5).

Written, informed consent approved by the local independent ethics committee, the Ethics Committee of the Faculty of Health Sciences of the University of the Free State and the South African Medicines Control Council was obtained from all participants prior to all study procedures. The study was conducted in accordance with the principles set forth in the Declaration of Helsinki as amended in Tokyo, 2004, and the Guidelines of the International Conference on Harmonization on Good Clinical Practice.

\subsection{Chemicals and drugs}

Micafungin was supplied in vials containing lyophilised micafungin powder $50 \mathrm{mg}$ plus lactose $200 \mathrm{mg}$, together with $0.9 \%$ sodium chloride solution for injection in $250 \mathrm{~mL}$ infusion bags.

\subsection{Drug administration}

On Day 1 each subject received a single infusion of micafungin $100 \mathrm{mg}$ at a constant rate of $100 \mathrm{~mL} / \mathrm{h}$ for $1 \mathrm{~h}$, administered intravenously via a cannula. Each subject 
received a total of $100 \mathrm{~mL}$ of intravenous dosing solution. Subjects remained supine during the entire infusion period.

\subsection{Blood sampling and assays}

Blood samples $(10 \mathrm{~mL})$ were collected by venous puncture or indwelling cannula of a forearm vein or veins (opposite arm to that receiving the infusion) into sodium heparinized tubes at the following times: pre-dose $(0 \mathrm{~h})$, $0.5,1 \mathrm{~h}$ (end of infusion), 1.25, 1.5, 2, 3, 4, 6, 8, 12, 16, $24,36,48,60,72$ and $96 \mathrm{~h}$ after the start of the micafungin infusion.

Plasma samples were prepared by protein precipitation using acetonitrile. Samples were centrifuged within $30 \mathrm{~min}$ of collection at $3,000 \mathrm{rpm}$ for $10 \mathrm{~min}$ at $\sim 4{ }^{\circ} \mathrm{C}$. For each sample, four aliquots of $0.5 \mathrm{~mL}$ of the resulting plasma fraction were prepared for PK analyses. The plasma concentrations of micafungin and its metabolites were determined using high-performance liquid chromatography with fluorescence detection following validated procedures (Groll et al. 2001; Yamato et al. 2002). The lower limit of quantification (LLOQ) of plasma micafungin and its metabolites M-1, M-2 and M-5 was $0.05 \mu \mathrm{g} /$ $\mathrm{mL}$.

In addition, two aliquots of plasma ( $1 \mathrm{~mL}$ each), from the blood samples collected 8 and $24 \mathrm{~h}$ after the start of infusion, were used for determination of micafungin plasma protein binding using an ultracentrifugation method. Protein-bound and unbound micafungin were separated using an ultrafiltration system (Centrifree ${ }^{\circledR}$ MPS3, Millipore, Merck KGaA, Darmstadt, Germany). Plasma samples were added to the filter reservoir of a micro-partition ultrafiltration device and centrifuged at 3,000 rpm for $15 \mathrm{~min}$ at $37{ }^{\circ} \mathrm{C}$. The resulting ultrafiltrate was analysed for unbound micafungin levels. The ratio of unbound micafungin to total micafungin in plasma was calculated as ultrafiltrate concentration/plasma concentration.

\subsection{PK analysis}

The PK parameters determined for micafungin and its metabolites were $C_{\max }, \mathrm{AUC}_{0-24}$, AUC from time 0 to the last quantifiable concentration $\left(\mathrm{AUC}_{\text {last }}\right), \mathrm{AUC}_{\infty}, t_{1 / 2}, \mathrm{CL}$ (micafungin only), volume of distribution $\left(V_{\mathrm{z}} ;\right.$ micafungin only) and volume of distribution at steady state $\left(V_{\mathrm{ss}}\right.$; micafungin only).

The $C_{\max }$ was obtained directly from plasma micafungin concentration-time data. $\mathrm{AUC}_{0-24}$ and $\mathrm{AUC}_{\text {last }}$ were calculated from the time of dosing to either the end of the dosing period or to the last measurable concentration of micafungin, respectively, by numeric integration using the linear trapezoidal rule for ascending concentrations and the $\log$ trapezoidal rule for descending concentrations, i.e.,
$\mathrm{AUC}_{(0-t)}=\sum_{i=0}^{n-1} \frac{t_{i+1}-t_{i}}{2}\left(C_{i}+C_{i+1}\right)$,

where $n$ is the number of data points, $0=$ $t_{0}<t_{1}<\cdots<t_{n}<t$ are sampling times, and $C_{i}$ is plasma micafungin concentration from the sample at $t_{i}$. $\mathrm{AUC}_{\infty}$ was estimated using

$\mathrm{AUC}_{\infty}=\mathrm{AUC}_{(0-t)}+\frac{C_{t}}{K_{\mathrm{e}}}$,

where $C_{t}$ is the last measurable plasma concentration of micafungin and $K_{\mathrm{e}}$ is the apparent terminal rate elimination constant obtained by log-linear regression of the terminal phase data. The $t_{1 / 2}$ values were defined using

$t_{1 / 2}=\frac{\ln (2)}{K_{\mathrm{e}}}$.

Plasma CL were calculated using the following formula:

$\mathrm{CL}=\frac{\mathrm{FD}}{\mathrm{AUC}_{\infty}}$,

where $F$ is the fraction of dose absorbed (which is presumed to be 1 as it was an IV infusion) and $D$ is the dose amount. Apparent $V_{\mathrm{z}}$ were calculated using

$V_{z}=\frac{\mathrm{FD}}{C_{0}}$,

where $C_{0}$ is the extrapolated plasma micafungin concentration at time 0 . Lastly, $V_{\mathrm{ss}}$ was calculated as

$V_{\mathrm{ss}}=\frac{D\left(\mathrm{AUMC}_{\infty}\right)}{\left(\mathrm{AUC}_{\infty}\right)^{2}}$

where AUMC is the area under the first-moment curve.

\subsection{Safety assessments}

Subjects were monitored for adverse events (AEs) throughout the study. Additional safety evaluations comprised vital signs assessment, physical examination, 12-lead electrocardiograms, urinalysis and urine microscopy and clinical laboratory measurements.

\subsection{Statistical analysis}

The PK analysis set included all subjects with evaluable PK data who completed the study. The safety analysis set included all subjects who received micafungin treatment. Descriptive statistics were used to analyse subject demographics, laboratory measurements, vital signs and $\mathrm{PK}$ data. Log-transformed values of $C_{\max }, \mathrm{AUC}_{0-24}, \mathrm{AUC}_{\text {last }}$, $\mathrm{AUC}_{\infty}, t_{1 / 2}$ and $\mathrm{CL}$ were analysed using an analysis of variance model with group as main effect using PROC MIXED of SAS (Version 8.2; SAS ${ }^{\circledR}$ Institute Inc., Cary, 
NC, USA). The mean ratios and $90 \%$ confidence intervals (CIs) for the mean differences on the logarithmic scale were transformed to obtain point estimates and $90 \% \mathrm{CIs}$ for the respective mean ratios. $90 \%$ CIs in the acceptance range of $80-125 \%$ were used to determine whether severe hepatic dysfunction altered the extent of micafungin exposure.

For subjects with severe hepatic dysfunction, multivariate linear regression analysis with stepwise selection was used to investigate the relationship between $C_{\max }, \mathrm{AUC}_{\infty}$ and CL for each plasma analyte (micafungin, M-1, M-2 and M-5) and hepatic function explanatory parameters (i.e. Child-Pugh score, plasma albumin, total bilirubin, prothrombin time and international normalised ratio).

All analyses, including calculation of PK parameters, were conducted by a central laboratory (FARMOVSPAREXEL, Bloemfontein, South Africa) using WinNon$\operatorname{lin}^{\circledR}$ Professional (Version 5.0.1, Pharsight Corporation, Mountain View, CA, USA).

\section{Results}

\subsection{Subjects}

Eight subjects with severe hepatic dysfunction and eleven subjects with normal hepatic function were included in this study. These 19 subjects comprised the safety analysis set. However, three of the subjects with normal hepatic function were excluded from the PK analysis due to protocol violations (involving processing of plasma aliquots from blood samples). Thus, the PK analysis set comprised the eight subjects with severe hepatic dysfunction and eight with normal hepatic function. Demographic characteristics of the study participants are shown in Table 1. Subjects were well matched for age, sex and body weight.

\subsection{PK analysis}

Mean plasma concentration versus time curves of micafungin in subjects with severe hepatic dysfunction and those with normal hepatic function are shown in Fig. 1. At each time point, the mean plasma micafungin concentration was lower in subjects with severe hepatic dysfunction compared with normal healthy subjects.

A summary of the micafungin PK parameters obtained in subjects with severe hepatic dysfunction and healthy subjects is shown in Table 2. Mean $C_{\max }, \mathrm{AUC}_{0-24}$, $\mathrm{AUC}_{\text {last }}$ and $\mathrm{AUC}_{\infty}$ were lower in subjects with severe hepatic dysfunction compared with healthy subjects. The mean ratios for $C_{\max }$ and $\mathrm{AUC}_{\infty}$ were $69.2 \%(90 \% \mathrm{CI}$ 51.3-93.5) and $68.2 \%$ (90\% CI 50.8-91.5), respectively. However, mean CL, $V_{\mathrm{z}}$ and $V_{\mathrm{ss}}$ were higher in subjects with
Table 1 Subject demographics

\begin{tabular}{lll}
\hline & $\begin{array}{l}\text { Subjects with } \\
\text { severe hepatic } \\
\text { dysfunction }\end{array}$ & $\begin{array}{l}\text { Subjects with } \\
\text { normal hepatic } \\
\text { function }\end{array}$ \\
\hline Number of subjects $(n)$ & 8 & 8 \\
Male, $n(\%)$ & $5(62.5)$ & $5(62.5)$ \\
Age, mean (SD), years & $54.5(8.6)$ & $50.1(6.3)$ \\
Weight, mean (SD) (kg) & $73.2(20.2)$ & $70.2(15.5)$ \\
Race, $n(\%)$ & & $2(25.0)$ \\
White & $2(25.0)$ & 0 \\
Coloured & $4(50.0)$ & $6(75.0)$ \\
Mixed race & $2(25.0)$ & \\
\hline
\end{tabular}

$S D$ standard deviation

${ }^{\text {a }}$ Ethnic group as defined in a South African context

severe hepatic dysfunction compared with healthy subjects (mean ratio for CL was $146.7 \%$ [90 \% CI 109.3-196.8]), while mean $t_{1 / 2}$ was similar in both groups.

Mean plasma concentration versus time curves of the metabolites M-1 and M-5 are shown in Fig. 2. Plasma concentrations of M-2 were below LLOQ $(0.05 \mu \mathrm{g} / \mathrm{mL})$ at all time points; therefore, no PK parameters were derived for this metabolite. Plasma concentrations of M-1 metabolite were below LLOQ in all subjects with severe hepatic dysfunction at all time points $\leq 12 \mathrm{~h}$ post-dosing and in all but one subject with severe hepatic dysfunction at the 16-h post-dose time point. Plasma concentrations of the M-1 metabolite were also below LLOQ in all subjects with normal hepatic function at all time points up to $16 \mathrm{~h}$ postdosing. From $24 \mathrm{~h}$ post-dosing, mean M-1 plasma concentrations were similar in both groups.

For all subjects with severe hepatic dysfunction, plasma concentrations of M-5 metabolite were measurable from 1-75 h post-dosing, but below LLOQ for three of these subjects at the $96-\mathrm{h}$ post-dose time point. For all healthy subjects, plasma concentrations of M-5 metabolite were measurable from $1.5-60 \mathrm{~h}$ post-dosing and below LLOQ at the $96-\mathrm{h}$ post-dose time point. At all time points, mean M-5 metabolite plasma concentrations were higher in subjects with severe hepatic dysfunction compared with healthy subjects.

A summary of the PK parameters of the M-1 metabolite in subjects with severe hepatic dysfunction and in healthy subjects is shown in Table 3. Mean $\mathrm{AUC}_{\infty}$ and $t_{1 / 2}$ were lower in subjects with severe hepatic dysfunction compared with healthy subjects. Point estimates for the ratios of $\mathrm{AUC}_{\infty}$ and $t_{1 / 2}$ between the two groups were $79.5 \%$ (90\% CI 44.9-140.8) and $70.0 \%$ (90\% CI 29.4-166.5), respectively. Mean $C_{\max }$ was similar in both groups.

PK parameters for the M-5 metabolite in subjects with severe hepatic dysfunction and in subjects with normal 
Fig. 1 Plasma micafungin concentration versus time profiles (geometric mean $\pm \mathrm{SD}$ ) for subjects with severe hepatic dysfunction $(n=8)$ and normal hepatic function $(n=8)$

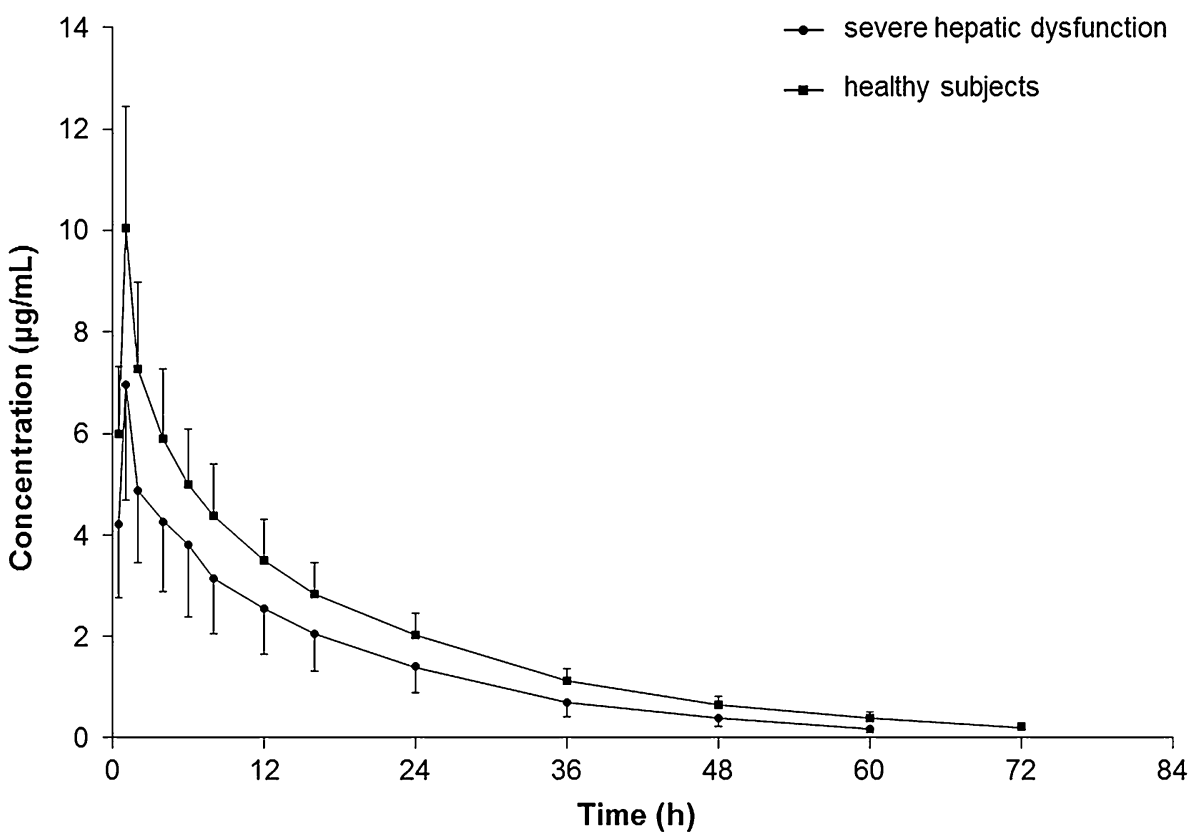

Table 2 PK parameters of micafungin [geometric mean (SD)] in subjects with severe hepatic dysfunction and normal hepatic function

\begin{tabular}{|c|c|c|c|c|}
\hline \multirow[t]{2}{*}{ Parameter } & \multirow{2}{*}{$\begin{array}{l}\text { Subjects with severe } \\
\text { hepatic dysfunction }(n=8)\end{array}$} & \multirow{2}{*}{$\begin{array}{l}\text { Subjects with normal } \\
\text { hepatic function }(n=8)\end{array}$} & \multicolumn{2}{|l|}{ ANOVA results } \\
\hline & & & Mean ratio $(\%)^{\mathrm{a}}(90 \% \mathrm{CI})$ & Coefficient of variation $(\%)$ \\
\hline$C_{\max }(\mu \mathrm{g} / \mathrm{mL})$ & $7.3(2.4)$ & $10.3(2.5)$ & $69.2(51.3-93.5)$ & 28.5 \\
\hline $\mathrm{AUC}_{0-24}(\mathrm{~h} \cdot \mu \mathrm{g} / \mathrm{mL})$ & $71.6(24.5)$ & $96.8(20.7)$ & $72.0(53.6-96.5)$ & 27.9 \\
\hline $\mathrm{AUC}_{\text {last }}(\mathrm{h} \cdot \mu \mathrm{g} / \mathrm{mL})$ & $98.2(34.3)$ & $140.6(29.0)$ & $67.7(50.4-91.1)$ & 28.2 \\
\hline $\mathrm{AUC}_{\infty}(\mathrm{h} \cdot \mu \mathrm{g} / \mathrm{mL})$ & $100.1(34.5)$ & $142.4(28.9)$ & $68.2(50.8-91.5)$ & 27.9 \\
\hline$t_{1 / 2}(\mathrm{~h})$ & $13.7(2.1)$ & $14.9(1.5)$ & $91.2(79.5-104.5)$ & 12.8 \\
\hline $\mathrm{CL}(\mathrm{mL} / \mathrm{h})$ & $1,098(347)$ & 728 (149) & $146.7(109.3-196.8)$ & 27.9 \\
\hline$V_{\mathrm{z}}(\mathrm{mL})$ & $21,283(5847)$ & $15,742(3979)$ & $\mathrm{NC}$ & $\mathrm{NC}$ \\
\hline$V_{\mathrm{SS}}(\mathrm{L})$ & $19,903(5670)$ & $14,693(3351)$ & $\mathrm{NC}$ & $\mathrm{NC}$ \\
\hline
\end{tabular}

ANOVA analysis of variance, $\mathrm{NC}$ not calculated

${ }^{a}$ Log-transformed mean value in subjects with severe hepatic dysfunction; log-transformed mean value in subjects with normal hepatic function

hepatic function are summarised in Table 3. Mean $C_{\max }$, $\mathrm{AUC}_{0-24}, \mathrm{AUC}_{\text {last }}$ and $\mathrm{AUC}_{\infty}$ were higher in subjects with severe hepatic dysfunction compared with healthy subjects. Point estimates for the ratios of $C_{\max }$ and $\mathrm{AUC}_{\infty}$ were $227.5 \%(90 \%$ CI $155.2-333.5)$ and $231.8 \%(90 \%$ CI 152.3-352.7), respectively. However, the $t_{1 / 2}$ of M-5 was similar in both subject groups.

To examine a potential cause for the different PK profiles between the study groups, free plasma protein concentrations were evaluated in eight subjects with severe hepatic dysfunction and 11 healthy subjects. Mean serum albumin concentrations were lower in subjects with severe hepatic dysfunction $[24.3 \pm 7.1 \mathrm{~g} / \mathrm{L}$ (Day 1), $22.6 \pm 6.9 \mathrm{~g} / \mathrm{L}$ (Day 2) and $24.3 \pm 8.6 \mathrm{~g} / \mathrm{L}$ (Day 5)] compared with healthy subjects $[39.4 \pm 2.1 \mathrm{~g} / \mathrm{L}$ (Day-1), $36.5 \pm 3.2 \mathrm{~g} / \mathrm{L}$ (Day 2) and $38.5 \pm 3.1 \mathrm{~g} / \mathrm{L}$ (Day 5)].

Plasma protein binding of micafungin was assessed in all subjects but was only measurable in five subjects with severe hepatic dysfunction and three healthy subjects. The ratios of unbound plasma micafungin concentration (ultrafiltrate) to total plasma micafungin concentration ranged from 0.024 to 0.139 (86.1-97.6\% protein binding) in subjects with severe hepatic dysfunction and from 0.010 to 0.076 (92.4-99.0\% protein binding) in healthy subjects. Ultrafiltrate micafungin concentrations were below LLOQ in the remaining subjects.

Linear regression analyses, conducted to examine the relationships between PK parameters and hepatic 

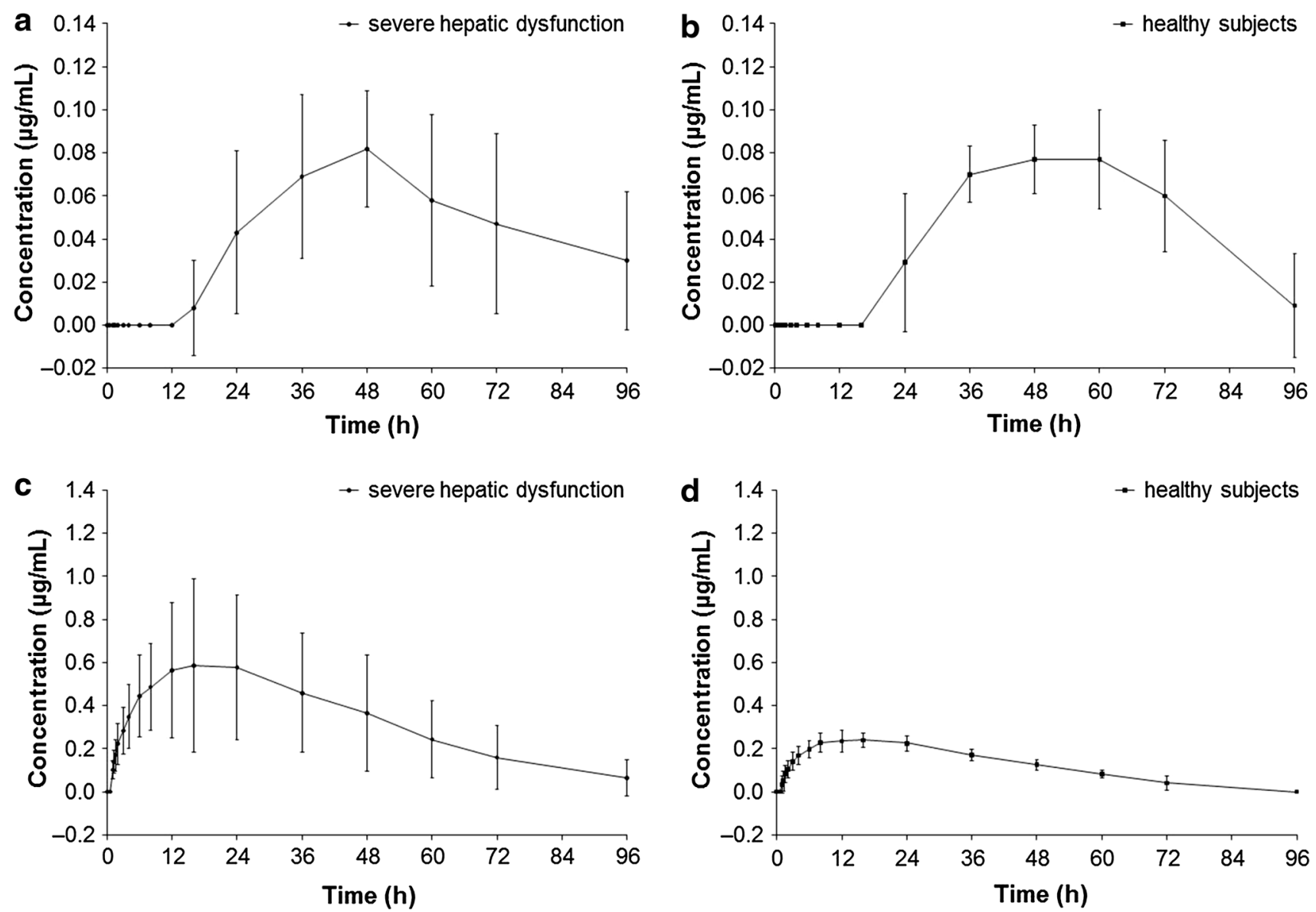

Fig. 2 Plasma concentration versus time profiles (arithmetic mean \pm SD) for the micafungin metabolites, M-1 (a, b) and M-5 (c, d), in subjects with severe hepatic dysfunction $(n=8)$ and normal hepatic function $(n=8)$

measurements, revealed a trend toward a positive linear relationship between the CL of micafungin and ChildPugh score $(P=0.0568)$, and positive linear relationships between both $C_{\max }$ and $\mathrm{AUC}_{\infty}$ of M-5 metabolite and total bilirubin $(P<0.05$ in each $)$.

\subsection{Safety assessments}

Safety was evaluated in eight subjects with severe hepatic dysfunction and eleven healthy subjects. Six AEs were reported by four subjects: one subject with severe hepatic dysfunction experienced dizziness and pruritus, and another experienced nausea and vomiting; while one healthy subject experienced headache and another experienced pruritus. None of these AEs was considered to be serious or to be related to micafungin, and none led to discontinuation of the study. No clinically significant changes in laboratory measures were reported at the end of study, including alanine aminotransferase, aspartate aminotransferase, or bilirubin levels and prothrombin time.

\section{Discussion}

In this study, micafungin plasma concentrations and most PK parameters were lower in subjects with severe hepatic dysfunction, except for CL, which was higher in these subjects; however, the magnitude of the differences was not considered to be clinically meaningful. These findings are consistent with a previous study of micafungin, in which subjects with moderate hepatic dysfunction displayed lower $C_{\max }$ and AUC values, but higher CL, compared with healthy subjects (Hebert et al. 2005b). Likewise, in a study of anidulafungin, there was a $33 \%$ lower exposure in subjects with severe hepatic dysfunction compared with healthy controls (Dowell et al. 2007).

The recommended dose for the treatment of adults with invasive candidiasis and candidaemia in adults is $100 \mathrm{mg}$ daily resulting in the mean steady-state $\mathrm{AUC}_{0-24}$ of $97 \mathrm{~h} \cdot \mu \mathrm{g} / \mathrm{mL}$ (Undre et al. 2012b). In the present study, a dose of $100 \mathrm{mg}$ yielded a mean $\mathrm{AUC}_{\infty}$ of $100.1 \mathrm{~h} \cdot \mu \mathrm{g} / \mathrm{mL}$ in subjects with severe hepatic dysfunction. These findings 
Table 3 PK parameters of micafungin metabolites, M-1 and M-5 [geometric mean (SD)], in subjects with severe hepatic dysfunction and normal hepatic function

\begin{tabular}{|c|c|c|c|c|}
\hline \multirow[t]{2}{*}{ Parameter } & \multirow{2}{*}{$\begin{array}{l}\text { Subjects with severe hepatic } \\
\text { dysfunction }(n=8)^{\mathrm{a}}\end{array}$} & \multirow{2}{*}{$\begin{array}{l}\text { Subjects with normal hepatic } \\
\text { function }(n=8)^{\mathrm{a}}\end{array}$} & \multicolumn{2}{|l|}{ ANOVA results } \\
\hline & & & Mean ratio $(\%)^{\mathrm{b}}(90 \% \mathrm{CIs})$ & Coefficient of variation $(\%)$ \\
\hline \multicolumn{5}{|l|}{ Metabolite M-1 } \\
\hline$C_{\max }(\mu \mathrm{g} / \mathrm{mL})$ & $0.1(0.0)$ & $0.1(0.0)$ & $102.2(77.2-135.1)$ & 26.5 \\
\hline $\begin{array}{l}\mathrm{AUC}_{0-24}(\mathrm{~h} \cdot \mu \mathrm{g} / \\
\mathrm{mL})\end{array}$ & $0.2(0.3)$ & $0.1(0.1)$ & $133.5(69.2-257.3)$ & 43.2 \\
\hline $\mathrm{AUC}_{\text {last }}(\mathrm{h} \cdot \mu \mathrm{g} / \mathrm{mL})$ & $3.9(2.6)$ & $3.5(1.6)$ & $88.0(38.7-199.7)$ & 89.2 \\
\hline $\mathrm{AUC}_{\infty}(\mathrm{h} \cdot \mu \mathrm{g} / \mathrm{mL})$ & $13.1(5.1)$ & $17.5(11.9)$ & $79.5(44.9-140.8)$ & 48.0 \\
\hline$t_{1 / 2}(\mathrm{~h})$ & $98.5(69.6)$ & $154.0(147.3)$ & $70.0(29.4-166.5)$ & 78.2 \\
\hline \multicolumn{5}{|l|}{ Metabolite M-5 } \\
\hline$C_{\max }(\mu \mathrm{g} / \mathrm{mL})$ & $0.6(0.4)$ & $0.2(0.0)$ & $227.5(155.2-333.5)$ & 36.8 \\
\hline $\begin{array}{l}\mathrm{AUC}_{0-24}(\mathrm{~h} \cdot \mu \mathrm{g} / \\
\mathrm{mL})\end{array}$ & $11.5(6.4)$ & $4.9(0.9)$ & $218.1(153.3-310.2)$ & 33.8 \\
\hline $\mathrm{AUC}_{\text {last }}(\mathrm{h} \cdot \mu \mathrm{g} / \mathrm{mL})$ & $31.0(20.9)$ & $10.8(1.7)$ & $251.2(164.5-383.6)$ & 41.1 \\
\hline $\mathrm{AUC}_{\infty}(\mathrm{h} \cdot \mu \mathrm{g} / \mathrm{mL})$ & $34.1(23.4)$ & $12.9(1.8)$ & $231.8(152.3-352.7)$ & 40.7 \\
\hline$t_{1 / 2}(\mathrm{~h})$ & $21.1(2.7)$ & $21.6(4.9)$ & $99.1(82.0-119.7)$ & 17.8 \\
\hline
\end{tabular}

${ }^{\mathrm{a}} n=8$ for all parameters except for $\mathrm{AUC}_{\infty}$ and $t_{1 / 2}$ in subjects with severe hepatic dysfunction $(n=5)$, and for the ANOVA calculation of mean ratio of $\mathrm{AUC}_{0-24}(n=4)$

${ }^{b}$ Log-transformed mean value in subjects with severe hepatic dysfunction; log-transformed mean value in subjects with normal hepatic function

suggest that dose adjustment is not required in subjects with severe hepatic dysfunction.

Plasma concentrations of the M-1 metabolite were negligible in the first $24 \mathrm{~h}$, suggesting a very slow rate of formation of this metabolite. For later time points, the plasma concentration profile of the M-1 metabolite was similar between the two study groups. Mean plasma concentrations of the M-5 metabolite, and its mean $C_{\max }$ and AUC values, were higher and more variable in subjects with severe hepatic dysfunction compared with healthy subjects. This suggests that patients with severe hepatic impairment exhibit either a higher rate of formation or lower CL of M-5 compared with healthy subjects; however, it is unknown which mechanism is responsible for this observation. The PK of the M-1 and M-5 metabolites has not been examined in subjects with moderate hepatic dysfunction in previous studies.

As micafungin is metabolised in the liver prior to its elimination, exposure would be expected to be higher in subjects with severe hepatic dysfunction due to disrupted micafungin metabolism. However, the PK profiles obtained for micafungin and its metabolites suggest the opposite as micafungin exposure was higher in healthy subjects with normal hepatic function than in subjects with severe hepatic dysfunction.

Micafungin is highly protein bound in plasma ( $>99 \%$ ) (Astellas Pharma; Hebert et al. 2005b), primarily to albumin. Plasma albumin concentrations are often altered in the presence of severe hepatic dysfunction, raising the possibility that altered plasma albumin concentrations may have impacted micafungin PK in subjects with severe hepatic dysfunction (Hebert et al. 2005b). Consistent with this hypothesis, subjects with severe hepatic dysfunction in this study had lower concentrations of plasma albumin than subjects with normal hepatic function. This resulted in an increase in free drug levels in the subjects with severe hepatic dysfunction which, in turn, led to increased CL in these individuals. This may also explain why mean micafungin $C_{\max }$ and AUC values were lower in subjects with hepatic dysfunction, but $t_{1 / 2}$ remained unchanged.

Micafungin is one of three available echinocandin antifungal agents. Existing evidence suggests that higher exposure to caspofungin is associated with moderate hepatic dysfunction and that this can be adjusted for using dose reduction (Merck Sharp \& Dohme Limited 2011; Mistry et al. 2007; van der Elst et al. 2012). Anidulafungin is not metabolised by the liver, and, therefore, dose adjustments are not required in subjects with mild, moderate or severe hepatic dysfunction (Pfizer Inc 2010).

Although systemic exposure to micafungin was lower in subjects with severe hepatic dysfunction in this study, the magnitude of this difference was not considered clinically meaningful. Micafungin has demonstrated efficacy in adults with invasive candidiasis and candidaemia, and in adults with HIV and oesophageal candidiasis, at levels of exposure similar to those attained in the present study (Undre et al. 2012a, b). Furthermore, a comparison of the free concentration of micafungin in the two populations showed that the fraction unbound is similar in the two populations. Thus, despite lower total micafungin 
exposure, the free concentrations considered to be pharmacologically active were similar, suggesting that dose adjustments are not required in subjects with severe hepatic dysfunction. In addition, a single dose of micafungin $100 \mathrm{mg}$ was well tolerated in subjects with severe hepatic dysfunction and subjects with normal hepatic function, and there were no safety concerns throughout the study.

\section{Conclusion}

In summary, the findings of the present study indicate that although severe hepatic dysfunction affects micafungin $\mathrm{PK}$, the magnitude of changes is not considered clinically meaningful and thus does not warrant dose adjustment in these individuals. This study also provides additional evidence showing that micafungin is well tolerated in subjects with hepatic dysfunction after a single dose of $100 \mathrm{mg}$.

Acknowledgments This study was sponsored by Astellas. Medical writing and editorial support was provided by Neil M. Thomas, $\mathrm{PhD}$, of Envision Scientific Solutions, funded by Astellas.

Conflict of interest Nasrullah Undre is an employee of Astellas Pharma Europe Ltd., Chertsey, UK. Paul Stevenson was formerly an employee of Astellas Pharma GmbH Munich, Germany. Benjamin Pretorius was formerly an employee of Parexel International, South Africa.

Open Access This article is distributed under the terms of the Creative Commons Attribution Noncommercial License which permits any noncommercial use, distribution, and reproduction in any medium, provided the original author(s) and the source are credited.

\section{References}

Astellas Pharma (2013) Mycamine: summary of product characteristics. http://www.ema.europa.eu/docs/en_GB/document_library/ EPAR_-_Product_Information/human/000734/WC500031075. pdf. Accessed 19 March 2012

Benjamin DK Jr, Smith PB, Arrieta A, Castro L, Sánchez PJ, Kaufman D, Arnold LJ, Kovanda LL, Sawamoto T, Buell DN, Hope WW, Walsh TJ (2010) Safety and pharmacokinetics of repeat-dose micafungin in young infants. Clin Pharmacol Ther 8œ7(1):93-99. doi:10.1038/clpt.2009.200

de Wet NT, Bester AJ, Viljoen JJ, Filho F, Suleiman JM, Ticona E, Llanos EA, Fisco C, Lau W, Buell D (2005) A randomized, double blind, comparative trial of micafungin (FK463) vs. fluconazole for the treatment of oesophageal candidiasis. Aliment Pharmacol Ther 21(7):899-907. doi:10.1111/j.13652036.2005.02427.x

Dowell JA, Stogniew M, Krause D, Damle B (2007) Anidulafungin does not require dosage adjustment in subjects with varying degrees of hepatic or renal impairment. J Clin Pharmacol 47(4):461-470. doi:10.1177/0091270006297227

Fromtling RA (2002) Micafungin sodium (FK-463). Drugs Today (Barc) 38(4):245-257
Groll AH, Mickiene D, Petraitis V, Petraitiene R, Ibrahim KH, Piscitelli SC, Bekersky I, Walsh TJ (2001) Compartmental pharmacokinetics and tissue distribution of the antifungal echinocandin lipopeptide micafungin (FK463) in rabbits. Antimicrob Agents Chemother 45(12):3322-3327. doi:10.1128/ AAC.45.12.3322-3327.2001

Hebert MF, Blough DK, Townsend RW, Allison M, Buell D, Keirns J, Bekersky I (2005a) Concomitant tacrolimus and micafungin pharmacokinetics in healthy volunteers. J Clin Pharmacol 45(9):1018-1024. doi:10.1177/0091270005279274

Hebert MF, Smith HE, Marbury TC, Swan SK, Smith WB, Townsend RW, Buell D, Keirns J, Bekersky I (2005b) Pharmacokinetics of micafungin in healthy volunteers, volunteers with moderate liver disease, and volunteers with renal dysfunction. J Clin Pharmacol 45(10):1145-1152. doi:10.1177/0091270005279580

Hebert MF, Townsend RW, Austin S, Balan G, Blough DK, Buell D, Keirns J, Bekersky I (2005c) Concomitant cyclosporine and micafungin pharmacokinetics in healthy volunteers. J Clin Pharmacol 45(8):954-960. doi:10.1177/0091270005278601

Jarvis B, Figgitt DP, Scott LJ (2004) Micafungin. Drugs 64(9): 969-982

Keirns J, Sawamoto T, Holum M, Buell D, Wisemandle W, Alak A (2007) Steady-state pharmacokinetics of micafungin and voriconazole after separate and concomitant dosing in healthy adults. Antimicrob Agents Chemother 51(2):787-790. doi:10.1128/ AAC.00673-06

Kuse ER, Chetchotisakd P, da Cunha CA, Ruhnke M, Barrios C, Raghunadharao D, Sekhon JS, Freire A, Ramasubramanian V, Demeyer I, Nucci M, Leelarasamee A, Jacobs F, Decruyenaere J, Pittet D, Ullmann AJ, Ostrosky-Zeichner L, Lortholary O, Koblinger S, Diekmann-Berndt H, Cornely OA (2007) Micafungin versus liposomal amphotericin $\mathrm{B}$ for candidaemia and invasive candidosis: a phase III randomised double-blind trial. Lancet 369(9572):1519-1527. doi:10.1016/S0140-6736(07)60605-9

Lass-Flörl C (2009) The changing face of epidemiology of invasive fungal disease in Europe. Mycoses 52(3):197-205

Merck Sharp \& Dohme Limited (2011) Cancidas (caspofungin) summary of product characteristics. Merck Sharp \& Dohme Limited. http://www.medicines.org.uk/emc/medicine/12843\# PHARMACOKINETIC_PROPS. Accessed 19 March 2012

Messer SA, Diekema DJ, Boyken L, Tendolkar S, Hollis RJ, Pfaller MA (2006) Activities of micafungin against 315 invasive clinical isolates of fluconazole-resistant Candida spp. J Clin Microbiol 44(2):324-326. doi:10.1128/JCM.44.2.324-326.2006

Mistry GC, Migoya E, Deutsch PJ, Winchell G, Hesney M, Li S, Bi S, Dilzer S, Lasseter KC, Stone JA (2007) Single- and multipledose administration of caspofungin in patients with hepatic insufficiency: implications for safety and dosing recommendations. J Clin Pharmacol 47(8):951-961. doi:10.1177/009127000 7303764

Pappas PG, Rotstein CM, Betts RF, Nucci M, Talwar D, De Waele JJ, Vazquez JA, Dupont BF, Horn DL, Ostrosky-Zeichner L, Reboli AC, Suh B, Digumarti R, Wu C, Kovanda LL, Arnold LJ, Buell DN (2007) Micafungin versus caspofungin for treatment of candidemia and other forms of invasive candidiasis. Clin Infect Dis 45(7):883-893. doi:10.1086/520980

Pfaller MA, Diekema DJ (2007) Epidemiology of invasive candidiasis: a persistent public health problem. Clin Microbiol Rev 20(1):133-163. doi:10.1128/CMR.00029-06

Pfizer Inc. (2010) Eraxis ${ }^{\mathrm{TM}}$ (anidulafungin) prescribing information. Pfizer Inc., http://labeling.pfizer.com/ShowLabeling.aspx?id= 566. Accessed 19 March 2012

Undre N, Stevenson P, Baraldi E (2012a) Pharmacokinetics of micafungin in HIV positive patients with confirmed esophageal candidiasis. Eur J Drug Metab Pharmacokinet 37(1):31-38. doi:10.1007/s13318-011-0063-8 
Undre N, Stevenson P, Kuse ER, demeyer I (2012b) Pharmacokinetics of micafungin in adult patients with invasive candidiasis and candidemia. Open J Med Microbiol 2(3):84-90. doi:10.4236/ ojmm.2012.23012

Undre NA, Stevenson P, Freire A, Arrieta A (2012c) Pharmacokinetics of micafungin in pediatric patients with invasive candidiasis and candidemia. Pediatr Infect Dis J 31(6):630-632. doi:10.1097/INF.0b013e31824ab9b0

van Burik JA, Ratanatharathorn V, Stepan DE, Miller CB, Lipton JH, Vesole DH, Bunin N, Wall DA, Hiemenz JW, Satoi Y, Lee JM, Walsh TJ (2004) Micafungin versus fluconazole for prophylaxis against invasive fungal infections during neutropenia in patients undergoing hematopoietic stem cell transplantation. Clin Infect Dis 39(10):1407-1416. doi:10.1086/422312 van der Elst KC, Brüggemann RJ, Rodgers MG, Alffenaar JW (2012) Plasma concentrations of caspofungin at two different dosage regimens in a patient with hepatic dysfunction. Transpl Infect Dis 14(4):440-443. doi:10.1111/j.1399-3062.2011.00716.x

Wiederhold NP, Lewis JS 2nd (2007) The echinocandin micafungin: a review of the pharmacology, spectrum of activity, clinical efficacy and safety. Expert Opin Pharmacother 8(8):1155-1166. doi: $10.1517 / 14656566.8 .8 .1155$

Yamato Y, Kaneko H, Tanimoto K, Katashima M, Ishibashi K, Kawamura A, Terakawa M, Kagayama A (2002) Simultaneous determination of antifungal drug, micafungin, and its two active metabolites in human plasma using high-performance liquid chromatography with fluorescence detection. Jpn J Chemother 50:68-73 